\title{
Leiomyosarcoma and Endometrial Stromal Sarcoma pT2a TNM Finding v7
}

National Cancer Institute

\section{Source}

National Cancer Institute. Leiomyosarcoma and Endometrial Stromal Sarcoma pT2a

TNM Finding v7. NCI Thesaurus. Code C89590.

Tumor involves adnexa. (from AJCC 7th Ed.) 